\title{
Selective inhibition of PDGFR by imatinib elicits the sustained activation of ERK and downstream receptor signaling in malignant glioma cells
}

\author{
YUCUI DONG ${ }^{1,2^{*}}$, LIMIN JIA ${ }^{1,2^{*}}$, XIAOHUA WANG ${ }^{1,2}$, XIAOQING TAN $^{1,2}$, JIANKAI XU $^{3}$, \\ ZHENLING DENG ${ }^{1,2}$, TAO JIANG ${ }^{4}$, NIKOLAI G. RAINOV ${ }^{5}$, BAOXIN LI ${ }^{6}$ and HUAN REN ${ }^{1,2}$ \\ ${ }^{1}$ Department of Immunology, Harbin Medical University; ${ }^{2}$ Immunity and Infection Key Laboratory of \\ Heilongjiang Province; ${ }^{3}$ College of Bioinformatics, Harbin Medical University, Harbin $150081 ;{ }^{4}$ Neurosurgery Institute, \\ Beijing Tiantan Hospital, Beijing 100005, P.R. China; ${ }^{5}$ Department of Neurosurgery, Klinikum Augsburg, \\ D-86156 Augsburg, Germany; ${ }^{6}$ Department of Pharmacology, Harbin Medical University, Harbin 150081, P.R. China
}

Received August 25, 2010; Accepted October 21, 2010

DOI: $10.3892 /$ ijo.2010.861

\begin{abstract}
Clinical studies using the tyrosine kinase inhibitor, imatinib mesylate $\left(\right.$ Gleevec $\left.^{\circledR}\right)$, in glioblastoma, have shown no major inhibition of tumor growth or extension of survival for patients, unlike those in chronic myeloid leukemia (CML) and gastrointestinal stromal tumors. The molecular mechanisms of action of imatinib in glioblastoma cells are still not well understood. In this study, we investigated the effects of imatinib on the platelet derived growth factor receptor (PDGFR) downstream signaling pathways as well as on other cellular functions in human glioblastoma cells. NIH3T3 fibroblast and K562 CML cells were used for comparison. Western blot analysis demonstrated that imatinib was more effective in inhibiting the activated rather than the quiescent forms of the target proteins. Furthermore, the imatinib treatment induced the sustained activation of extracellular signalregulated kinase (ERK 1/2) signaling as well as components of other downstream signaling pathways, such as PI3K/Akt, STAT3 and p38MAPK. Prior stimulation of the malignant cells with exogenous PDGF-BB partially abrogated this activation. Further analysis indicated that the activation of ERK induced by the imatinib treatment was related to the S-phase re-entry of the cell cycle in one of the three glioma cells. Imatinib significantly inhibited cell migration but not cell growth. The combination treatment of imatinib with a MEK or PI3K inhibitor resulted in significant growth inhi-
\end{abstract}

Correspondence to: Professor Huan Ren, Department of Immunology, Harbin Medical University, 157 Baojian Road, Harbin 150081, P.R. China

E-mail: huan_ren@hotmail.com; renhuan@ems.hrbmu.edu.cn

*Contributed equally

Key words: glioblastoma, imatinib mesylate, extracellular signalregulated kinase, tyrosine kinase inhibitor, cell signaling pathways, targeted therapy bition but did not inhibit cell migration beyond the inhibition achieved with the imatinib treatment alone. The treatment of glioma cells with small interfering RNA inhibiting PDGFRB, however, evoked enhanced Akt signaling. These results indicate that the imatinib treatment of malignant glioma does not result in significant inhibitory effects and should be used with caution.

\section{Introduction}

The prognosis of patients with malignant gliomas, including WHO grade IV glioblastoma multiforme (GBM), remains poor despite improved treatment modalities, such as maximum surgical resection, radiotherapy and oral chemotherapy with temozolomide (1). Over the years, a number of frequent genetic alterations have been identified in human glioblastomas. These generally affect three critical signaling pathways, including signal transduction pathways activated by receptor tyrosine kinases (RTKs), as well as cell apoptotic and cell cycle growth arrest pathways (2). Molecular targeting is thus becoming increasingly important in malignant glioma treatment. Increased signaling from overactive and/or overexpressed RTKs is a hallmark of malignant gliomas $(3,4)$. These RTKs are mostly growth factor receptors, including the platelet derived growth factor receptor (PDGFR), the vascular endothelial growth factor receptor (VEGFR) and the epidermal growth factor receptor (EGFR). Anti-RTK-based strategies using small molecule kinase inhibitors or antibodies have been tested in clinical trials for patients with malignant glioma. These were focused on the inhibition of excessive RTK activity and thus of the downstream cellular signaling cascades that are responsible for enhanced proliferation, angiogenesis and the survival of cancer cells (3,5-7). Among others, two major intracellular signaling pathways that are activated by RTKs and are co-opted in tumor cells are the Ras/MAPK and PI3K/Akt/mTOR pathways.

Research data from human glioma biopsies have indicated that the increased expression of different PDGF ligands and receptor subtypes in high grade glioma could allow the PDGFR autocrine/paracrine loop to be closed, thus leading to 
the constitutive auto-activation of PDGFR and downstream signaling pathways, which could contribute to the pathogenesis of these tumors (8-10). Pre-clinical evidence has not only shown an important role for the overexpression and excessive activation of PDGFR-mediated signaling in tumorigenesis and the maintenance of the malignant phenotype, but has also proven that the targeted inhibition of signaling cascades has significant anti-cancer effects (11-13). Kilic et al (12) found that treatment with the small molecule kinase inhibitor, imatinib, inhibited the growth of human malignant glioma cells in the brains of nude mice at concentrations that are also achievable in humans. These data presented support for the potential therapeutic value of PDGFR inhibitors in patients with malignant glioma.

Similar to many small molecule RTK inhibitors, imatinib binds to the ATP-binding pocket of the target kinase, competing with ATP and thus blocking kinase activity. This mechanism has been proven for PDGFRA, PDGFRB, the stem cell factor receptor, c-Kit, and Bcr-Abl kinases (14). Imatinib has shown remarkable effects not only in patients with chronic myeloid leukemia (CML) and Bcr-Abl activation, but has also been proven to inhibit c-Kit- and PDGFRAmediated signaling and to improve survival in patients with gastrointestinal stromal cell tumors (15) and hypereosinophilic syndrome (16). However, phase I/II clinical studies with single-agent imatinib have failed to demonstrate significant clinical effects in patients with malignant glioma $(5,17)$. Although results from phase II studies on the agent in combination with hydroxyurea, have suggested beneficial effects and have supported the initiation of a randomized clinical trial (18), this trial was eventually halted due to proven lack of efficacy (7). Further studies on the targeted inhibition of selected downstream pathways, i.e. PI3K, by combinations of imatinib with hydroxyurea, are currently underway (7). So far the responses observed in clinical studies using imatinib in malignant glioma have been too few to allow the identification of reliable and reproducible biomarkers for predicting response and survival $(5,17-20)$.

Published data have suggested that clinical failures result from a multitude of reasons. Besides the choice of an irrelevant target, other reasons include resistance development, co-activation of alternative tyrosine kinases, independent constitutive activation of intracellular molecular effectors downstream of the targeted protein, activation of upstream components through loss of negative feedback, and receptor transactivation leading to constitutive activity (7). Currently, combinations of targeted agents have been proposed and are being tested. Such strategies include targeting parallel tyrosine kinases receptor pathways simultaneously, targeting one specific pathway at more than one level, and blocking both upstream and downstream components $(4,7)$.

In the present study, a panel of glioblastoma cell lines was used in order to account for the heterogeneity of human gliomas. In these cells, the cellular and molecular effects of imatinib were investigated and compared to control cells, such as K562 CML cells expressing Bcr-Abl, and NIH3T3 mouse fibroblast cells expressing PDGFR. We focused on the functional alterations of receptor and non-receptor protein kinases and on their possible interactions within related downstream signaling pathways. The main rationale of the study was to identify the cellular responses to imatinib in glioma cells and to emphasize that, as cellular signaling functions in network rather than linear pathways, investigating and understanding the properties of key cell signaling networks is an important step before applying any signal transduction inhibitor drugs, either alone or in combination with other agents.

\section{Materials and methods}

Protein kinase inhibitors. Imatinib mesylate (STI571, Gleevec $^{\circledR}$ ) was obtained from Novartis Pharma GmbH (Nuremberg, Germany) and was dissolved in distilled water to a final stock solution concentration of $10 \mathrm{mM}$. The solution was filtered through a $0.22-\mu \mathrm{m}$ sterile syringe filter (Corning Inc., Corning, NY), aliquoted and stored at $-20^{\circ} \mathrm{C}$. The MEK inhibitors, PD98059 and U0126, and the PI3K inhibitor, LY294002, were purchased from Sigma-Aldrich (Shanghai, China), the EGFR inhibitor, erlotinib (OSI-774, Tarceva ${ }^{\circledR}$ ), was obtained from Roche GmbH (Kulmbach, Germany), and the multi-target inhibitor, sunitinib (SU11248, Sutent ${ }^{\circledR}$ ), was obtained from Pfizer Pharma GmbH (Berlin, Germany). All these substances were dissolved in DMSO, aliquoted and stored at $-20^{\circ} \mathrm{C}$. Cell culture medium was used to serially dilute stock solutions to the required final concentrations.

Cell culture and protein kinase inhibitor treatment. The human malignant glioma cell lines, T98G, U87MG, LNZ308 and RG, the human leukemia cell line, K562, and the mouse embryonic cell line, NIH3T3, were used in this study. T98G, U87MG, LNZ308, K562 and NIH3T3 were obtained from the ATCC (Manassas, VA). RG was established through the serial passaging of a resected human GBM, as previously described (21). Glioma cell lines and NIH3T3 were grown in monolayer and maintained in DMEM (Sigma-Aldrich, Irvine, UK), K562 suspension cells were grown and maintained in RPMI-1640 (Sigma), and they were both supplemented with $10 \%$ heat inactivated fetal calf serum (FCS) (Sigma), $2 \mathrm{mM}$ L-glutamine (Sigma), and 1\% penicillin/streptomycin (Gibco Life Technologies, Paisley, UK) in a $5 \% \mathrm{CO}_{2}$ incubator in a humidified atmosphere of $37^{\circ} \mathrm{C}$. All the cells were serially passaged every 2-3 days when they were $70-80 \%$ confluent. Cell conditions for growth factor stimulation are indicated below.

For cells treated with imatinib and other protein kinase inhibitors, low-serum conditions were applied unless specified, using $0.5 \%$ FCS rather than $10 \%$ FCS during each treatment. Briefly, cells were seeded at the appropriate density and grown $12-24 \mathrm{~h}$ in standard cell culture conditions with $10 \%$ FCS, and the culture medium was then replaced by lowserum medium (DMEM containing $0.2 \%$ FCS) for another $24 \mathrm{~h}$ to synchronize the cells for further treatment regimens. Different treatment regimens were then carried out on the cells with $0.5 \%$ FCS culture medium under varied concentrations of inhibitor treatment over various time courses before the cells were harvested for analysis. Where indicated, varied control groups were used.

PDGF-AA and PDGF-BB growth stimulation. Cells were grown to $50 \%$ confluence and cell quiescence was induced 
by replacing the standard medium with a low-serum medium (DMEM containing $0.2 \% \mathrm{FCS}$ ) for $24 \mathrm{~h}$ in 96 -well plates (5000 cells/well) prior to the start of the experiments. Quiescent cells were then stimulated for $48 \mathrm{~h}$ with one of the following: PDGF-AA (50 ng/ml), $50 \mathrm{ng} / \mathrm{ml}$ PDGF-BB, or DMEM containing $0.2 \%$ FCS (controls, no stimulation). Cell proliferation was measured by standard microplate MTT assays. Briefly, $4 \mathrm{~h}$ before the end of cell culture, the culture medium was replaced by DMEM with $0.5 \mathrm{mg} / \mathrm{ml}$ MTT (Sigma) and the cells were incubated for another $4 \mathrm{~h}$ at $37^{\circ} \mathrm{C}$. MTT was then removed and the intracellular formazan crystals were solubilized in $100 \mu 1$ isopropanol/0.1 N HCl according to the manufacturer's instructions. Absorbance was measured at 570 and $630 \mathrm{~nm}$ (as a reference wavelength) on a microplate reader (ELx800, BioTek Instruments, Heidelberg, Germany).

Western blot analysis. Lysates were generated by placing cells in cell lysis buffer (Cell Signaling Technology, Danvers, MA). Bradford assays (Bio-Rad, Herts, UK) were performed to determine total protein concentrations, which were normalized to $1 \mu \mathrm{g} / \mu 1$ for all samples. Samples were then prepared in sample buffer and run on polyacrylamide gels. Up to $30 \mu 1$ of protein lysates in sample buffer from each group were loaded within each well, including the controls. Primary antibodies directed against total- and phospho-P44/42 MAPK, total-Akt, phospho-Akt (Thr308), phosphotyrosine clone 4G10 (Upstate Biotechnology, Shanghai, China), phosphorylated and total PDGFRB (Santa Cruz, USA), total EGFR (Invitrogen Ltd., Shanghai), phosphorylated and total STAT3, phos-phorylated and total p38MAPK, and B-actin (antibodies were purchased from Cell Signaling Technology if not mentioned otherwise), and secondary antibody (antirabbit HRP-conjugated; Cell Signaling Technology), were applied. Enhanced chemiluminescence (Pierce Ltd., Shanghai) detection was then used and the levels of proteins and phospho-proteins were quantified by densitometry using NIH-Image ${ }^{\circledR}$. The ratio of the mean density of phospho- to that of total-protein/ $/$-actin was calculated and recorded as the relative expression level of the protein activity.

Small interfering RNA (siRNA) gene knockdown of PDGFRB. U87MG cells were seeded at $8 \times 10^{4}$ cells per $60-\mathrm{mm}$ petri dish without antibiotics and were allowed grow in monolayer for $24 \mathrm{~h}$. Stealth ${ }^{\mathrm{TM}}$ RNA (60 $\mathrm{nM}$ ) (3 pairs including PDGFRBHSS 107758, PDGFRB-107759 and PDGFRB-107760 against PDGFRB and siRNA negative control, NC-siRNA 12935-300 Medium GC Duplex; Invitrogen Co., Ltd.) was transfected using Lipofectamine 2000 (Invitrogen) and applied according to the manufacturer's instructions. Normal tissue culture medium was replaced after $8 \mathrm{~h}$ and total RNA and protein from the cells in each dish were harvested 48-72 $\mathrm{h}$ after siRNA transfection. Total RNA $(1 \mu \mathrm{g})$ from each sample was reverse-transcribed and $50 \mathrm{ng}$ of cDNA input were amplified and analyzed by real-time PCR as indicated below. Real-time PCR was run on both PDGFRB and B-actin (set as the internal control) to compare the rate of gene knockdown. Each measurement was performed in duplicate. Protein lysates were extracted and Western blot analysis on total PDGFRB was employed as indicated above to detect targeted gene expression at the protein level after the PDGFRB gene knockdown by siRNA.

Protein kinase assays. Semi-quantitative immunoblot analyses for the detection of the phosphorylation status of 37 known protein kinase phosphorylation sites (KPSS-2.0, Kinexus Bioinformatics Corp., Vancouver, Canada), and that of further 33 known protein kinase phosphorylation sites (KPSS-5.0, Kinexus Bioinformatics Corp.), were carried out. These Kinetworks $^{\mathrm{TM}}$ multi-immunoblots have been optimised to detect band-shifts on SDS-PAGE gels, which can arise from different phosphorylation states of the respective protein kinases (see www.kinexus.ca for details). The U87MG glioma cells treated with $15 \mu \mathrm{M}$ imatinib and $10 \%$ FCS for 4 days, as well as the untreated controls, were lysed with cell lysis buffer including protease and protein phosphatase inhibitors. Cell lysates were assayed for protein content using a Bradford protein assay kit (Bio-Rad). The final protein concentration of the lysates was adjusted at $1 \mathrm{mg} / \mathrm{ml}$ for the SDS-PAGE analysis.

Cell growth inhibition assays. Standard microplate MTT assays as described above in the PDGF-AA and PDGF-BB growth stimulation section, were carried out with a panel of malignant glioma cells, as well as NIH3T3 and K562 cells to evaluate the growth inhibition effect of the treatment with increasing concentrations of imatinib $(0,1,3,5,10 \mu \mathrm{M})$. Briefly, glioma, NIH3T3 and K562 cells were plated at a density of $2 \times 10^{3}$ cells per well in 96-well microplates with $10 \%$ FCS, and treated with varying concentrations of drugs in a total volume of $200 \mu 1$ culture medium per well. Additional MTT assays were carried out with U87MG cells to evaluate the growth inhibition effect of the imatinib treatment, alone or in combination with the MEK inhibitor, PD98059, or with the PI3K inhibitor, LY294002 (both from Sigma-Aldrich). DMSO (Sigma-Aldrich) was used as the solvent for the latter two inhibitors and was therefore included in the controls at the same concentration. According to the $50 \%$ effective inhibition concentration $\left(\mathrm{IC}_{50}\right)$ reported in relevant studies (22), two concentrations of PD98059, 20 and $50 \mu \mathrm{M}$, and two of LY294002, 7.5 and $15 \mu \mathrm{M}$, respectively, were chosen and combined with increasing concentrations of imatinib: $0,2.5,5,10,20$ and $50 \mu \mathrm{M}$.

Cell migration assays. Cell migration was quantified using a modified monolayer migration assay which measures the dispersion of a cell population on surfaces (23). Ten-well HTC-treated slides (Dynex Technologies, Denkendorf, Germany) were coated with AES (3-aminopropyltriethoxysilane) (Sigma) to optimize cell adhesion. Slides were then passively coated with extracellular matrix protein solution $(100 \mu \mathrm{g} / \mathrm{ml})$ and a cell sedimentation manifold (CSM) (Creative Scientific Methods, Mesa, AZ) containing $50 \mu 1$ of culture medium was placed over the slides. Cells were seeded in a volume of $1 \mu 1\left(2 \times 10^{3}\right.$ cells $)$, and the slides were then incubated for $48 \mathrm{~h}$ at $37^{\circ} \mathrm{C}$. The CSM was removed and the circular area occupied by the attached cells in each well was quantified with a CCD-based image analysis system (Quantimed 500, Leica, Hamburg, Germany). Object sizes were measured by a single observer as the radius in $\mu \mathrm{m}$ of 
the circular area covered by a cell population. Serial images were captured for up to $48 \mathrm{~h}$. Quantitative migration scores were calculated as the increase of the radius beyond the initial radius of the object and migration rates were determined by regression analysis. These measurements represent the radius increase of the cell population due to cells migrating outward from the rim area of the colony.

Monolayer wound healing assay. Glioma cells were seeded and grown with $10 \%$ FCS for $24 \mathrm{~h}$ as a confluent monolayer in each well of six-well culture dishes. Before plating into the dish, two parallel lines were drawn at the underside of the well with a Sharpie marker. These lines served as fiducial marks for the wound areas to be analyzed. In preparation for making the wound, the growth medium was aspirated and replaced by calcium-free PBS to prevent the destruction of cells at the edge of the wound by exposure to high calcium concentrations. Consistent wounds of $\sim 400 \mu \mathrm{m}$ in width were made perpendicular to the marker lines with a white P10 pipet tip (Fisher). This procedure makes it possible to image the entire width of the wound using a 10x objective. Culture medium with $0.5 \%$ FCS was replaced in the glioma cells with/without treatment with imatinib $(10 \mu \mathrm{M})$ alone or in combination with either the MEK inhibitor, U0126 $(15 \mu \mathrm{M})$, or the PI3K inhibitor, LY294002 $(15 \mu \mathrm{M})$. The wounds were observed using phase contrast microscopy. Images were taken at 0,24 and $48 \mathrm{~h}$ of both areas flanking the intersections of the wound and the marker lines ( 8 images per treatment). Images were analyzed by digitally drawing lines (using Adobe Photoshop, Adobe Corp., USA) averaging the position of the migrating cells at the wound edges. The cell migration distance was determined by measuring the width of the wound divided by two and by subtracting this value from the initial half-width of the wound.

Cell cycle analysis by flow cytometry. Cell cycle analysis was performed using the CycleTEST ${ }^{\text {тм }}$ PLUS DNA Reagent Kit (BD Biosciences, Oxford, UK) on a FACStrak flow cytometer equipped with CellQuest software. Before treatment, glioblastoma cells were prepared and synchronized as described in the afore-mentioned cell culture and protein kinase inhibitor treatment section. Glioblastoma cells treated either with different concentrations of imatinib alone, or $10 \mu \mathrm{M}$ imatinib with either U0126 $(15 \mu \mathrm{M})$ or LY294002 $(15 \mu \mathrm{M})$, or the untreated controls, were prepared and harvested at 8 , 24,48 , or 72 h, respectively. Propidium iodide staining was carried out, flow cytometric analysis was performed and cell cycle distribution was analyzed by ModFit LT $^{\text {тм }} 2.0$ software (Verity Software House, Cambridge, MA).

Immunofluorescence microscopy. Glioma cells with/without protein kinase inhibitor treatment were seeded onto glass coverslips in 12-well plates at a density of $2 \times 10^{4}$ per well. Bromodeoxyuridine (BrdU) $(10 \mu \mathrm{M})$ (Sigma-Aldrich, Shanghai) was added $1 \mathrm{~h}$ before the cells were fixed with $4 \%$ paraformaldehyde. Cells were then blocked in blocking buffer, which included $4 \%$ mouse serum, $1 \%$ bovine serum albumin and PBST $(0.1 \%$ Triton in PBS). For immunofluorescence staining, fixed glioma cells on coverslips were treated twice with $4 \mathrm{M} \mathrm{HCl}$ for $20 \mathrm{~min}$ each to allow the denaturation of DNA to its single-stranded form and were washed three times with PBS. Anti-BrdU-FITC-conjugate (1:50 in blocking buffer, Abcam Biotech Co., Ltd., Shanghai, China) was incubated for $4 \mathrm{~h}$ at room temperature in a humidity chamber followed by two PBS washes. Samples were mounted and the results were evaluated by fluorescence microscopy. The fluorescence quantification of cells on coverslips was viewed with a Nikon ECLIPSE 80i microscope and images were captured with a DS-Ril-U2 Cold-CCD camera. For analysis all the images were viewed and captured at 100x magnification. Triplicate slides were prepared at each time-point, and for each slide triplicate $425 \times 425-\mu \mathrm{m}$ fields were randomly selected. The same field was used to identify the numbers of total cells and cells expressing BrdU. Image analysis was performed using Image-Pro Plus (Media Cybernetics, Silver Spring, MA).

Statistics. All Western blot analyses were repeated at least twice. All other experiments were repeated at least three times and the results are expressed as the means \pm SD. Where appropriate, two group comparisons were analyzed with the Student's t-test and multiple group comparisons were analyzed with the one-way ANOVA Tukey test. P-values were calculated and values of $<0.05$ were considered to be statistically significant.

\section{Results}

PDGF-BB growth stimulation effects and effect of selective PDGFR inhibition on cell growth by imatinib treatment. We previously found by RT-PCR, that both PDGF ligands (PDGF-AA and PDGF-BB), as well as the two receptor subtypes (PDGFRA and PDGFRB) are present in all tested glioma cells used in this study, also indicating the presence of potential autocrine loops. c-Kit was only expressed in RG cells (21). Growth factor stimulation with PDGF-AA $(50 \mathrm{ng} / \mathrm{ml})$ had no effect on cell growth, whereas PDGF-BB $(50 \mathrm{ng} / \mathrm{ml})$ had a significant $(\mathrm{p}<0.05)$ growth stimulation effect on all tested glioma cells, with a maximal effect of $130 \pm 6.2 \%$ of the control in the LNZ308 glioma cell line (Fig. 1A). While PDGF-AA (50 ng/ml) stimulation showed no increase of phospho-PDGFRA by Western blot analyses in the tested glioma cells (data not shown), PDGF-BB (50 ng/ml for $10 \mathrm{~min}$ ) stimulation exerted significant effects on the enhanced phosphorylation of PDGFRB, which was low in the unstimulated glioma cells (Fig. 1B). In comparison, PDGF-BB (10 ng/ml for $10 \mathrm{~min})$ stimulated the phosphorylation of PDGFRB to a much greater degree in the NIH3T3 fibroblast cells, which served as the positive control for the rapid activation of PDGFR upon PDGF ligand stimulation (Fig. 1B).

To measure the effect of PDGFR inhibition on cell growth, the small molecule tyrosine kinase inhibitor, imatinib mesylate (imatinib), was used as a single drug in malignant glioma, NIH3T3 and K562 CML cells. Data showed that, with increasing concentrations of imatinib, growth inhibition was only achieved to a certain extent in the tested glioma cells at $10 \mu \mathrm{M}$. Unexpectedly, $5 \mu \mathrm{M}$ imatinib had a growth stimulation effect in two of the tested glioma cells, the RG and U87MG cells (Fig. 1C). Up to $5 \mu \mathrm{M}$ of imatinib 
A



B

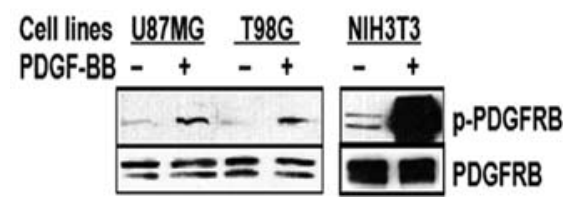

C



Figure 1. PDGF ligand stimulation effects on glioma cell growth, phosphorylation of PDGFRB, and imatinib effects on glioma cell proliferation. (A) PDGF-BB $(50 \mathrm{ng} / \mathrm{ml})$ had significant growth stimulation effect on U87MG, RG and LNZ308 glioma cells $(\mathrm{p}<0.05)$. Cells were serum-starved for $24 \mathrm{~h}$ prior to stimulation and harvested $48 \mathrm{~h}$ after stimulation. PDGF-AA at the same concentration $(50 \mathrm{ng} / \mathrm{ml})$ did not have a growth stimulation effect. (B) PDGF-BB $(50 \mathrm{ng} / \mathrm{ml})$ incubation for $10 \mathrm{~min}$ resulted in increased phosphorylation of PDGFRB in U87MG and T98G cells. Lower concentrations of the same ligand $(10 \mathrm{ng} / \mathrm{ml})$ for $10 \mathrm{~min}$ stimulated pronounced increase of phospho-PDGFRB in NIH3T3 fibroblast cells. (C) MTT (96-h) assays for measurement of growth inhibition effects of imatinib in glioma cells. The drug had limited growth inhibition activity in the tested glioma cells at concentrations of up to $10 \mu \mathrm{M}$. In U87MG and RG cells, $5 \mu \mathrm{M}$ imatinib showed a growth stimulation effect. Data are represented as the mean values of 3 independent experiments. Bars indicate standard deviations of the mean. ${ }^{*} \mathrm{p}<0.05$ and ${ }^{* *} \mathrm{p}<0.01$, statistical significance.

treatment inhibited the proliferation of NIH3T3 cells to a limited extent, while $10 \mu \mathrm{M}$ imatinib further inhibited the growth of the same cells (Table I). However, $1 \mu \mathrm{M}$ of imatinib effectively inhibited the proliferation of K562 cells, but concentrations of $>1 \mu \mathrm{M}$ did not further achieve higher rates of growth inhibition in the leukemia cells (Table I).

Efficacy of inhibition on PDGFRB activation by imatinib treatment could be related to the level of the target protein kinase activation prior to treatment. K562 CML cells expressing Bcr-Abl, NIH3T3 fibroblast cells and U87MG glioma cells expressing PDGFRB, were used to analyze the
Table I. Cell proliferation assays in NIH3T3 and K562 cells under imatinib treatment.

\begin{tabular}{lcc}
\hline & \multicolumn{2}{c}{ Cell viability (\% of control) } \\
\cline { 2 - 3 } Imatinib $(\mu \mathrm{M})$ & NIH3T3 cells & K562 cells \\
\hline 0 & $100 \pm 4.72$ & $100 \pm 6.15$ \\
1 & $83.03 \pm 1.79^{\mathrm{a}}$ & $26.15 \pm 1.54^{\mathrm{a}}$ \\
3 & $80.69 \pm 3.91^{\mathrm{a}}$ & $24.62 \pm 0.77^{\mathrm{a}}$ \\
5 & $80.44 \pm 2.61^{\mathrm{a}}$ & $23.38 \pm 0.30^{\mathrm{a}}$ \\
10 & $64.22 \pm 3.00^{\mathrm{a}}$ & $23.06 \pm 1.54^{\mathrm{a}}$ \\
\hline
\end{tabular}

MTT (96-h) assays were used for the measurement of growth inhibition effects of imatinib in NIH3T3 and K562 cells. The drug had limited growth inhibition activity in NIH3T3 with 10\% FCS at concentrations of up to $10 \mu \mathrm{M}$. In K562 cells, $1 \mu \mathrm{M}$ imatinib showed a significant growth inhibition effect. Concentrations of $>1 \mu \mathrm{M}$ did not further suppress cell growth in the Bcr-Abl-positive leukemia cell lines. Data are presented as the means \pm SD of three independent experiments. ${ }^{\mathrm{a}} \mathrm{p}<0.01$, compared to the respective untreated control.

efficacy of inhibition on the target protein kinase by imatinib treatment. Data showed that imatinib was more effective on inhibiting highly activated forms of the target protein kinases, as supported by data obtained from K562 cells whose BcrAbl kinase activity was high (Fig. 2A), ligand-stimulated NIH3T3 cells which expressed high levels of phosphoPDGFRB (Figs. 1B and 2B) and PDGF-BB-stimulated U87MG glioma cells whose PDGFRB was only relatively activated (Figs. 1B, 2D and F). Consistent with earlier reports, a high degree of inhibition on phospho-Bcr-Abl was observed with the imatinib treatment in the K562 cells, with an $\mathrm{IC}_{50}$ of $<0.2 \mu \mathrm{M}$ (Fig. 2A) $(14,24)$. In the ligand-stimulated NIH3T3 cells, $1 \mu \mathrm{M}$ of imatinib almost completely inhibited the activation of PDGFRB, although $10 \mu \mathrm{M}$ imatinib application did not result in a further increase of inhibition, indicating that a saturation effect could have been achieved at $1 \mu \mathrm{M}$ (Fig. 2B). However, if NIH3T3 cells were not stimulated by the ligand prior to the treatment, incubation of the cells with $1 \mu \mathrm{M}$ imatinib for $30 \mathrm{~min}$ stimulated the activation of PDGFRB, and further extension of the treatment to $8 \mathrm{~h}$ only decreased the level of the phospho-protein to that equivalent to the baseline (Fig. 2C). As relatively low activation of PDGFRB was observed in the ligand-stimulated and non-stimulated U87MG cells (Fig. 1B), increased concentrations and extended hours of imatinib treatment were applied in the U87MG glioma cells. Imatinib treatment $(10 \mu \mathrm{M})$ achieved inhibition of PDGFRB activation in the stimulated (Fig. 2D) and non-stimulated cells (Fig. 2E), especially during later hours of treatment, and it was used as a standard treatment in glioma cells for further investigations.

Furthermore, similar to the results obtained from the NIH3T3 cells without PDGF-BB stimulation (Fig. 2C), $30 \mathrm{~min}$ of $10 \mu \mathrm{M}$ imatinib treatment, which was carried out either before or after 10 min of PDGF-BB stimulation, slightly increased the phosphorylation of PDGFRB in U87MG cells. 
A



B



C

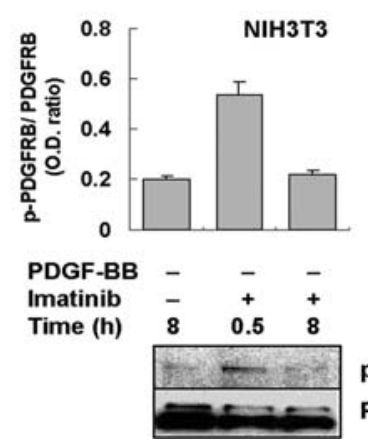

F

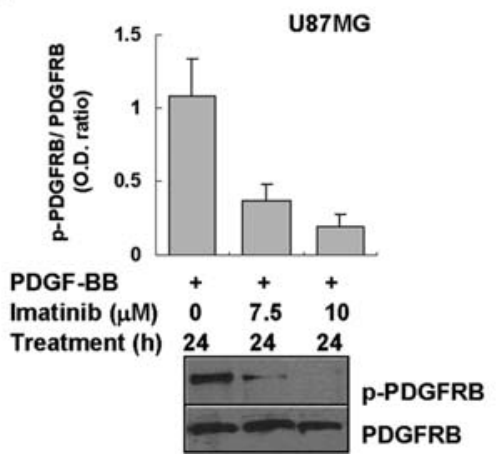

E

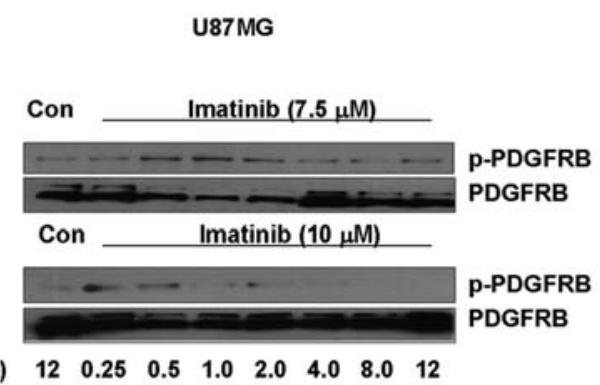

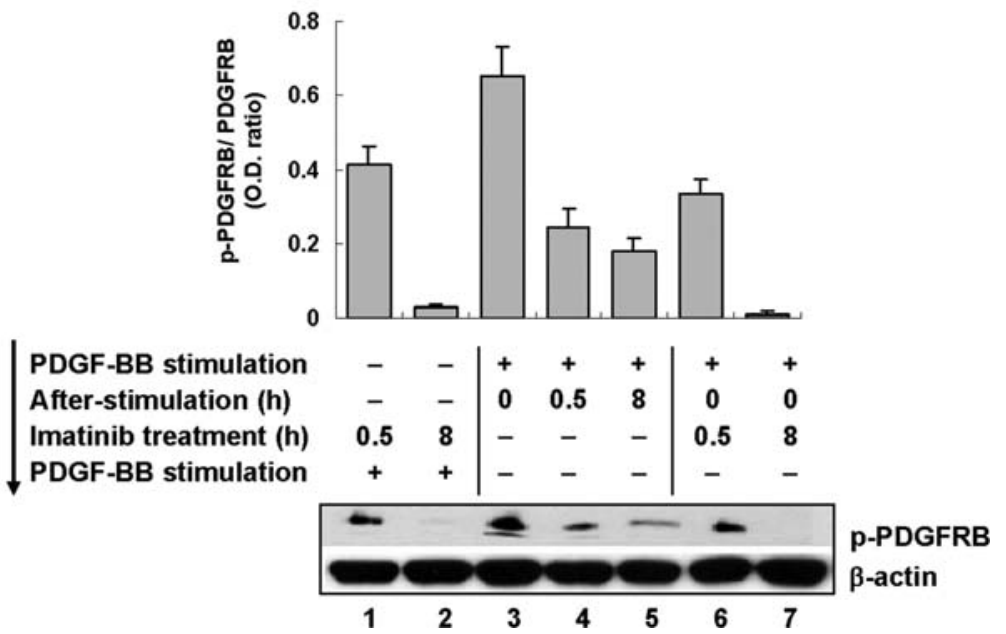

Figure 2. Efficacy and dynamics of target protein kinase inhibition by imatinib. (A) Western blot analysis indicated that imatinib inhibits the phosphorylated form of Bcr-Abl in K562 CML cells, with an $\mathrm{IC}_{50}$ of $<0.2 \mu \mathrm{M}$. (B) PDGF-BB (10 ng/ml) incubation for 10 min stimulated significant phosphorylation of PDGFRB in NIH3T3 fibroblast cells. Further application of $1 \mu \mathrm{M}$ imatinib significantly inhibited such PDGFRB activation. However, $10 \mu \mathrm{M}$ did not further inhibit the activation of PDGFRB, but stimulated the activation of PDGFRB compared to its level at $1 \mu \mathrm{M}$ imatinib. (C) Imatinib (1 $\mu \mathrm{M})$ in NIH3T3 cells without PDGF-BB stimulation inhibited PDGFRB activation to a limited extent at $8 \mathrm{~h}$ compared to the controls. Application of the same drug concentration for $30 \mathrm{~min}$ however, increased the activation of PDGFRB compared to that of the control. (D) Stimulation by PDGF-BB (50 $\mathrm{ng} / \mathrm{ml}$ for $10 \mathrm{~min}$ ) increased the activation of PDGFRB in U87MG glioblastoma cells, imatinib effectively inhibited the activation of PDGFRB at $24 \mathrm{~h}$ in a dose-dependent manner. (E) Both 7.5 and $10 \mu \mathrm{M}$ imatinib were ineffective in inhibiting the activation of PDGFRB in U87MG cells without PDGF-BB stimulation, compared to that in the controls. In addition, PDGFRB activation was unstable over the time-course of imatinib treatment. (F) The PDGF-BB stimulation (50 ng/ml for $10 \mathrm{~min})$ and treatment with imatinib $(10 \mu \mathrm{M}$ for either $30 \mathrm{~min}$ or $8 \mathrm{~h})$ were applied in U87MG cells in order from top to bottom as listed at the left of the graph. Imatinib treatment for $30 \mathrm{~min}$ increased the activation of PDGFRB in U87MG cells (lanes 1 and 6 compared to lane 4 on p-PDGFRB, respectively), while the same treatment inhibited the activation at $8 \mathrm{~h}$ (lanes 2 and 7 compared to lane 5 on p-PDGFRB, respectively), either before or after PDGF-BB stimulation. However, p-PDGFRB faded away over time upon withdrawal of the ligand in the same cells (lanes 3, 4 and 5). Quantification densitometry of Western blot bands was done using NIH Image $\mathrm{J}^{\circledR}$ and the ratio of p-PDGFR to PDGFRB or ß-actin was calculated. Data are presented as the mean values of 3-4 independent experiments. Bars indicate standard deviations of the mean. 
A

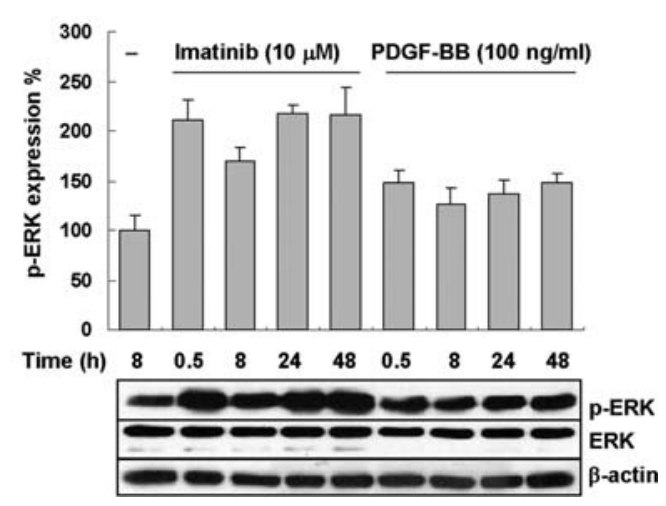

C



B

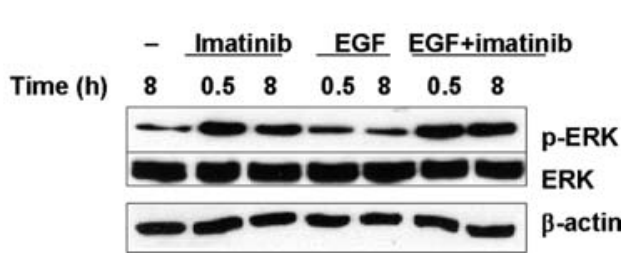

D

Culture time



$\mathbf{F}$

Treatment Con Imatinib+U0126 U0126 $\begin{array}{lllllllllll}\text { Time (h) } & 12 & 0.5 & 8 & 12 & 24 & 0.5 & 8 & 12 & 24\end{array}$

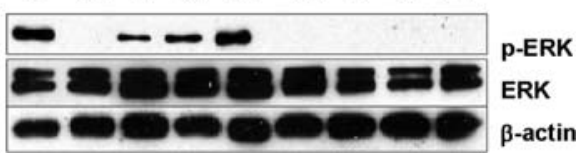

Figure 3. Activation of ERK by imatinib treatment in glioblastoma and NIH3T3 cells cultured with $0.5 \%$ FCS. The glioma and NIH3T3 cell preparation and various inhibitor treatment conditions are described in Materials and methods. (A) In U87MG cells with $0.5 \%$ FCS, $10 \mu \mathrm{M}$ imatinib induced the activation of ERK for up to $48 \mathrm{~h}$ and the level of expression was higher than that detected in the same cells stimulated by $100 \mathrm{ng} / \mathrm{ml} \mathrm{PDGF-BB}$ at the same period of time. (B) Comparison between the stimulatory effects of EGF $(20 \mathrm{ng} / \mathrm{ml})$, imatinib $(10 \mu \mathrm{M})$ and these two in combination on the activation of ERK, was carried out in U87MG cells. Imatinib treatment induced the increased activity of ERK as opposed to EGF. (C) The activation of ERK was induced by $10 \mu \mathrm{M}$ imatinib in glioblastoma cells, including T98G and RG cells, and NIH3T3 cells cultured with $0.5 \%$ FCS. (D) The activation of ERK remained constant and low in U87MG and T98G cells cultured for up to $48 \mathrm{~h}$ with $0.5 \%$ FCS. (E) ERK activation was completely inhibited in K562 cells by $0.6 \mu \mathrm{M}$ imatinib treatment for $4 \mathrm{~h}$. (F) Combination treatment with $10 \mu \mathrm{M}$ imatinib and the MEK inhibitor, $15 \mu \mathrm{M}$ U0126, only partially inhibited ERK activation for up to 24 h, while U0126 treatment alone completely abrogated ERK activation during the same period of time in the same cells. Data are represented from $2-3$ independent experiments.

The application of such concentrations of imatinib for $8 \mathrm{~h}$ completely inhibited PDGFRB phosphorylation. However, the natural fading of phospho-PDGFRB could explain the remaining results (Fig. 2F). These data indicate that imatinib could be ineffective on target inhibition if the activation level of the target protein kinase is relatively low, and that excessive doses of imatinib cannot achieve further effects.

Imatinib treatment elicits sustained activation of ERK in nonstimulated glioma and NIH3T3 fibroblast cells for up to $48 \mathrm{~h}$. Western blot analysis showed that the significant and sustained activation of ERK was induced by $10 \mu \mathrm{M}$ imatinib treatment in non-stimulated U87MG glioma cells cultured under low serum $(0.5 \%$ FCS $)$ conditions over the indicated time course. The extent of activation was even stronger than that observed in the same cells stimulated with $100 \mathrm{ng} / \mathrm{ml}$ PDGF-BB (Fig. 3A), as well as that in the same cells stimulated with $20 \mathrm{ng} / \mathrm{ml}$ EGF over an equal time period (Fig. 3B). Furthermore, this phenomenon was also observed in other glioma cells during imatinib treatment for up to $48 \mathrm{~h}$, e.g. T98G and RG glioma and NIH3T3 fibroblast cells, in which the previous PDGF-BB stimulation was absent (Fig. 3C). Additional examination in glioma cells without imatinib treatment, indicated that the level of ERK activation remained relatively consistent during the 48-h cell culture conditions in the U87MG and T98G cells (Fig. 3D). However, in the K562 cells, ERK activation was efficiently inhibited at a dose level equivalent to that of a complete inhibition of the target protein 
by imatinib treatment (Figs. 2A and 3E). These findings suggest that the activation of ERK induced by imatinib treatment could also be related to a certain threshold level of its target protein activation.

We further tested whether the combination treatment with imatinib and the MEK inhibitor, U0126, could significantly inhibit the ERK activation in U87MG cells. MEKs are kinases immediate upstream of ERK (MAPK) in Ras/MAPK signaling pathways (25). The results showed that, while U0126 treatment alone completely inhibited the activation of ERK, the combination treatment only partially abrogated the ERK activation that was stimulated by imatinib treatment (Fig. 3F). This implies that the interacting cellular signaling routes, rather than the signaling via MEK, also contribute to the activation of ERK resulting from imatinib treatment.

The activation pattern of RTKs downstream cell signaling pathways in U87MG cells varies under different treatment conditions. The activation of major downstream signaling pathways of RTKs could be induced directly or indirectly by imatinib treatment, as indicated by 24-h time-coursed analyses on the activities of ERK, Akt, STAT3 and p38MAPK etc. in non-stimulated U87MG cells cultured with $0.5 \%$ FCS, compared to the untreated controls (Fig. 4A, left panels). In order to examine whether the activation of these downstream signaling pathways by imatinib treatment is related to PDGFRB activation, the glioblastoma cells were stimulated with PDGF-BB (100 ng/ml for $10 \mathrm{~min}$ ) to increase p-PDGFRB levels prior to imatinib treatment. Data indicated that there was no further activation of the above proteins (including ERK) in the stimulated cells compared to the untreated controls (Fig. 4A, right panels). Together with the results obtained from K562 (Figs. 2A and 3E), NIH3T3 (Figs. 2B, $2 \mathrm{C}$ and $3 \mathrm{C}$ ) and U87MG cells (Figs. 2D, 2E and 3A), these data indicate that the activation level of the respective target protein kinase could control whether the imatinib treatment could result in the activation of downstream signaling components, including ERK, in the tested cells.

In order to further investigate the effects of imatinib treatment on the activation of downstream signaling of RTKs in normal cultured U87MG cells for up to $96 \mathrm{~h}, 15 \mu \mathrm{M}$ rather than $10 \mu \mathrm{M}$ of imatinib were employed as the normal tissue culture conditions with $10 \%$ FCS included mixed growth factors, which could continuously stimulate the activation of RTKs, e.g. PDGFR, EGFR, and VEGFR, in the glioma cells under the inhibitor treatment. The end-point analysis was done by multi-immunoblot analysis (KPSS 2.0 and KPSS 5.0, www.kinexus.ca). Data indicated the significant functional activation of ERK1/2, compared to the untreated controls, with more significant activation of ERK2, whereas the phosphorylation activity of other kinases was down-regulated (Fig. 4Ba). Most of the functionally inhibited kinases were effectors in the MAPK pathway, including the MAPK kinases MEK-1 (37\%) and -2 (20\%), SRC (45\%), p38 MAPK (28\%), and stress activated protein kinase $(50 \%)$. A second set of multi-immunoblots (KPSS 5.0) analyzed another 33 known protein kinase phosphorylation sites in U87MG cells and the results confirmed the prominent functional up-regulation of ERK 1 and 2 by imatinib treatment, whereas the phosphorylation activity of other protein kinases was inhibited
(Fig 4Bb). The inconsistent activation between ERK and other protein kinases in the glioma cells under this type of treatment condition is currently not understood.

Activation of ERK by the treatment of imatinib could be related to mechanisms other than the knockdown of the targeted gene expression in U87MG cells. Further analysis revealed that, various doses of imatinib, 5-20 $\mu \mathrm{M}$, did not affect the activation level of either ERK or Akt in U87MG cells with $0.5 \%$ FCS (Fig. 5A). Examination in NIH3T3 cells with $0.5 \%$ FCS also indicated that the imatinib treatment did not inhibit the activation of Akt during the indicated time course (Fig. 5B). These data suggest that the imatinib treatment did not inhibit the activation of the two key components in the two major RTK downstream signaling pathways, e.g., Ras/MAPK and PI3K/Akt signaling in both tested glioma and NIH3T3 cells, whose activation of PDGFRB was relatively low (Figs. 2C, 2E, 4A and 5A and B). We also found that, while the combination therapy with imatinib and the PI3K inhibitor, LY294002, inhibited the activation of Akt especially at the longer time-points of the treatment (Fig. 5C) in U87MG cells, the same treatment did not affect the activation of ERK stimulated by the imatinib treatment alone (Figs. 3A and 5C). This implies that the activation of Akt cannot be contributed to the ERK activation by imatinib treatment in the tested cells.

Furthermore, three pairs of siRNA specifically against PDGFRB were applied to the U87MG cells, in order to understand whether constitutive activation of ERK induced by imatinib treatment could be resulting from related feedback control mechanisms in RTK/Ras/ERK signaling pathways or other downstream signaling due to the loss of PDGFRB signaling, or whether the loss itself could induce such an effect. Two pairs of siRNA successfully inhibited PDGFRB expression with rates of inhibition of $>70 \%$ at the mRNA level (data not shown), leading to the loss of PDGFRB protein expression to different degrees (Fig. 5D). Data showed that while the level of p-ERK remained constant, p-Akt was significantly elevated in the cells treated by siRNA (Fig. 5D). This implies that, while not essential for the activation of ERK in glioblastoma cells, PDGFR signaling could be more related to downstream Akt signaling pathways.

Moreover, the co-activation of alternative RTKs has been demonstrated in a relevant study with glioma cell lines, in which the simultaneous multi-targeted therapy by combination of several RTK inhibitors proved to be necessary for the inhibition of the downstream PI3K signaling pathway (26). We also investigated whether ERK activation could be increased by treatment with other RTK inhibitors and/or whether the combination therapy could prevent the activation of downstream ERK signaling in U87MG cells. A concentration of the EGFR inhibitor, erlotinib $(10 \mu \mathrm{M})$ (OSI-774, Tarceva), was chosen according to this previous study (26). As sunitinib (SU11248, Sutent) is a multi-kinase inhibitor whose targets include PDGFRA, PDGFRB, VEGFR-1, -2 and -3 , FGF-R1, and Flt-3, two concentrations of the inhibitor, 70 and $130 \mathrm{nM}$, were chosen for the experiments. The former concentration was based on the fact that it inhibited the kinase activity of PDGFRA in vitro with an $\mathrm{IC}_{50}$ value of $70 \mathrm{nM}$, that of PDGFRB around $10 \mathrm{nM}$, and that of 
A

U87MG



Ba

U87MG

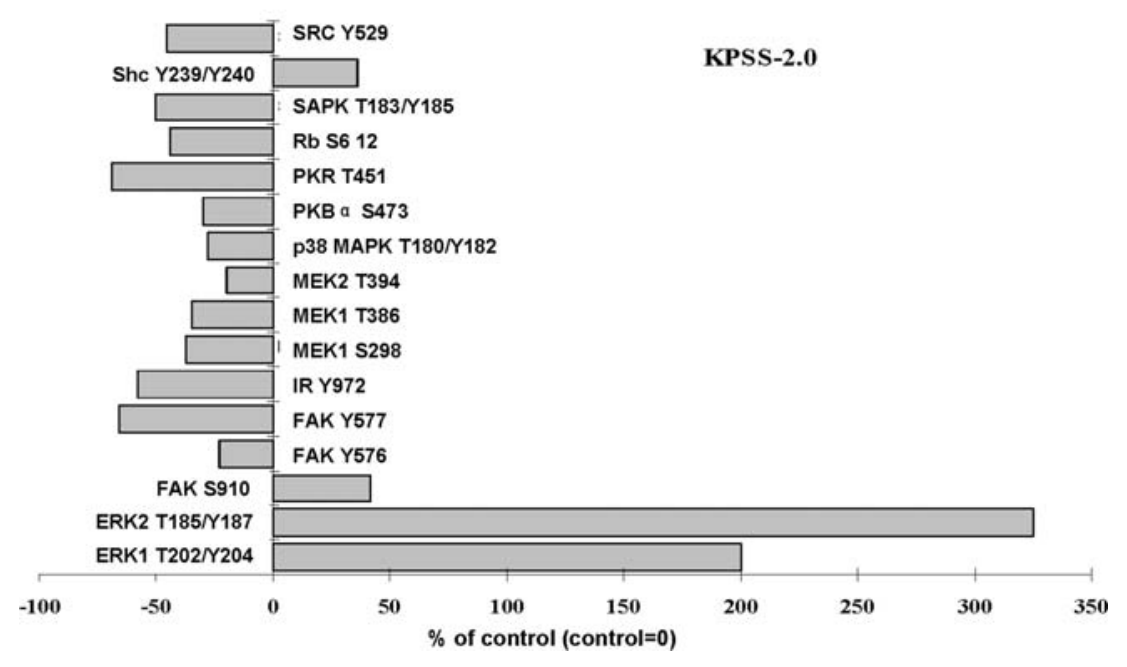

Bb

U87MG

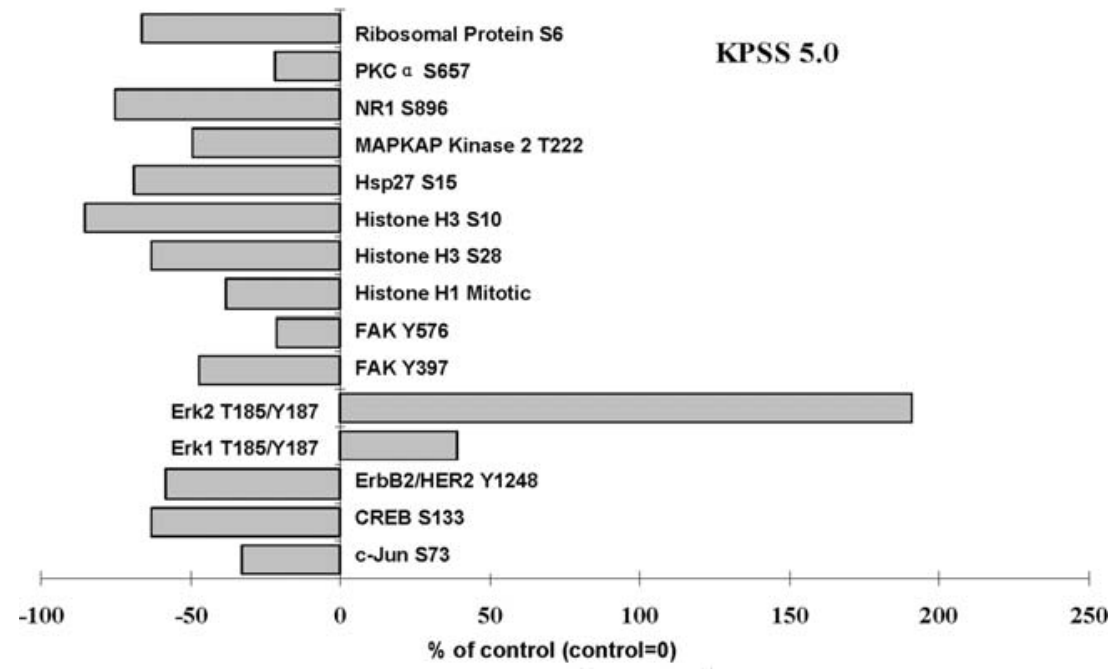

Figure 4. Imatinib treatment induced cellular signaling downstream of RTKs and activated ERK in U87MG cells. (A) Activation of key effectors in different downstream signaling pathways, including ERK, Akt, STAT3, and p38MAPK, was observed in U87MG cells cultured with $0.5 \%$ FCS and treated with $10 \mu \mathrm{M}$ imatinib, compared to the untreated controls (the left panels). Stimulation of the cells with PDGF-BB (100 ng/ml for $10 \mathrm{~min}$ ) prior to treatment did not result in further activation of the above key effectors (the right panels). These data are presented from 2-3 independent experiments. (B) Results from two multiimmunoblots, KPSS-2.0 (Ba) and KPSS-5.0 (Bb) (www.kinexus.ca) for the detection of 37 and 33 known protein kinase phosphorylation sites, respectively, in U87MG cells cultured with $10 \%$ FCS and with/without $15 \mu \mathrm{M}$ imatinib treatment for 4 days. ERK1/2 activation was confirmed in both blots (data not shown), while the activities of other kinases were decreased. The activity of the respective kinase in U87MG cells without imatinib treatment was set as 0 , kinases whose activity was $>/<25 \%$ were recorded and showed as columns either on the right $(+25 \%)$ or left $(-25 \%)$. 




c

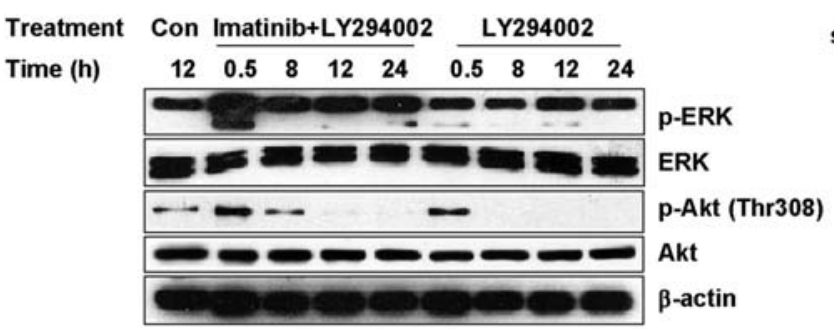

B

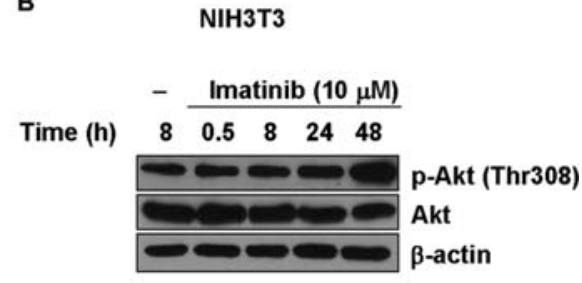

D

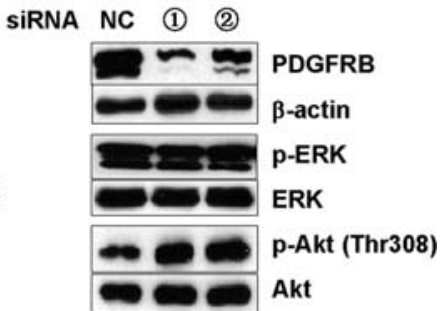

E

U87MG

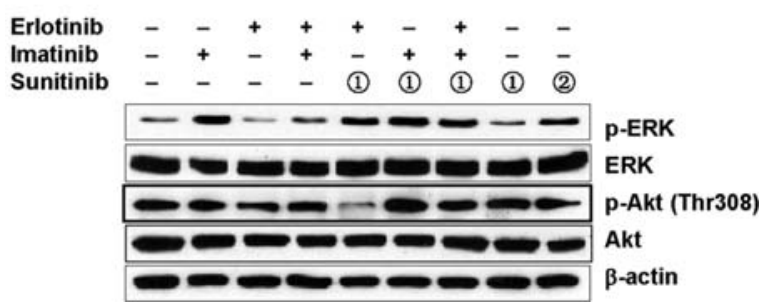

Figure 5. Mechanisms of ERK activation induced by imatinib treatment could be related to the efficacy of target inhibition. (A) Increased concentrations of imatinib induced the activation of both ERK and Akt in U87MG cells with $0.5 \%$ FCS. A significant increase in ERK and Akt activation was observed from $5 \mu \mathrm{M}$ up to $20 \mu \mathrm{M}$ of imatinib treatment at $8 \mathrm{~h}$, compared to that in the U87MG cells without treatment. The increase of the respective protein activation was similar among the treatment groups. (B) Imatinib treatment $(10 \mu \mathrm{M})$ did not inhibit the activation of Akt for up to $48 \mathrm{~h}$ in NIH3T3 cells cultured with $0.5 \%$ FCS. (C) Combination treatment with $10 \mu \mathrm{M}$ imatinib and the PI3K inhibitor, $15 \mu \mathrm{M}$ LY294002, did not affect the constitutive activation of ERK for up to $24 \mathrm{~h}$, while the same treatment completely abrogated Akt activation at longer treatment time-points in the same cells. (D) siRNA against PDGFRB was successfully applied in U87MG cells (data not shown at the mRNA level), leading to reduced levels of PDGFRB expression at the protein level. While ERK activation was not affected, p-Akt (Thr308) was significantly elevated by siRNA treatment. (E) Treatment with RTK inhibitors in U87MG cells for $1 \mathrm{~h}$ for the activation of ERK or Akt. Single inhibitor treatment with either erlotinib (EGFR inhibitor) or 70 nM sunitinib (the multiple kinase inhibitor on VEGFR, PDGFR etc.) reduced ERK activation. Besides the activation of ERK induced by imatinib treatment alone, significant activation of ERK was also induced by combination treatments with erlotinib and imatinib, sunitinib and imatinib, and $130 \mathrm{nM}$ sunitinib alone. Significant inhibition on the activation of Akt was only observed in cells under the combination treatment of erlotinib and $70 \mathrm{nM}$ sunitinib. Imatinib $(10 \mu \mathrm{M})$ and the same concentration of erlotinib were used in all the sets of the experiment. In addition, two concentrations of sunitinib were applied. 1, $70 \mathrm{nM} ; 2,130 \mathrm{nM}$. Data are presented from 2-3 independent experiments.

VEGFR at $<40 \mathrm{nM}$ (27). The latter concentration was significantly higher, assuming a better inhibitory effect on the downstream ERK signaling pathways. Our data showed significant activation of ERK in U87MG cells as the result of the combination treatments with $10 \mu \mathrm{M}$ erlotinib and $70 \mathrm{nM}$ sunitinib, $10 \mu \mathrm{M}$ imatinib and $70 \mathrm{nM}$ sunitinib, $10 \mu \mathrm{M}$ erlotinib with $70 \mathrm{nM}$ sunitinib and $10 \mu \mathrm{M}$ imatinib, and $130 \mathrm{nM}$ sunitinib alone, besides the $10 \mu \mathrm{M}$ imatinib treatment alone (Fig. 5E). In the remaining groups, ERK activation was down-regulated (Fig. 5E). However, only the combination treatments with $10 \mu \mathrm{M}$ erlotinib and $70 \mathrm{nM}$ sunitinib significantly inhibited the activation of Akt in the cells (Fig. 5E). Although the imatinib treatment did not enhance the activation of EGFR in U87MG and T98G cells (data not shown), the combination treatment with erlotinib and imatinib partially abrogated the activation of ERK, compared to the imatinib treatment alone (Fig. 5E). The mechanisms involved in both the activation of ERK and thee lack of inhibition on Akt activation in the tested glioma cells under some of the inhibitor combination treatments are currently not understood. However, as we only tested the effects of various treatment regimens on the activation of Akt and ERK over a 1-h timepoint, further time course analyses are required, which could shed some light on the mechanisms involved.

Imatinib treatment promotes cell proliferation and decreases cell migration in U87MG cells. The results from MTT assays (Figs 1C and 6A), cell cycle analyses and anti-BrdU fluorescent staining (Fig. 6B) in U87MG cells treated with imatinib, either alone or in combination with the MEK inhibitor, PD98059, suggested that the constitutive activation of ERK and other downstream effectors induced by imatinib treatment could be correlated with enhanced glioma cell proliferation. In MTT assays, enhanced cell proliferation was obtained with $5 \mu \mathrm{M}$ imatinib treatment in some of the tested glioma cells, including U87MG (Fig. 1C), and with $10 \mu \mathrm{M}$ in U87MG cells in a separate experimental setting (21). Other studies using malignant glioma cells (including U87MG, 
A



U87MG

B


c

U87MG

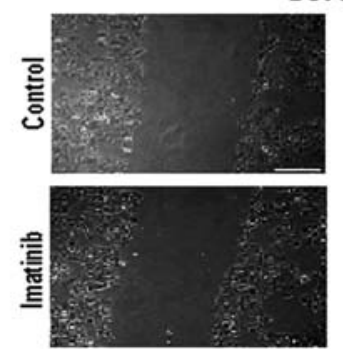

TIme 0
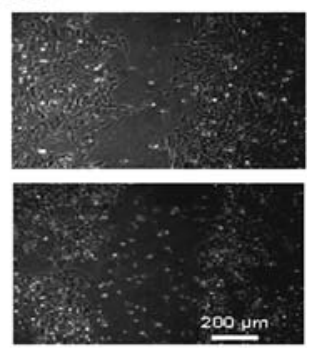

TIme $48 \mathrm{~h}$
D



Figure 6. ERK activation could result in enhanced cell proliferation in U87MG cells treated with imatinib. (A) Combination treatment with either the MEK inhibitor, PD98059, or the PI3K inhibitor, LY294002, significantly reduced imatinib resistance in U87MG cells ( $\mathrm{p}<0.05$ at 5 and $10 \mu \mathrm{M}$ imatinib). Combination treatment with PD98059 $(50 \mu \mathrm{M})$ resulted in the $\mathrm{IC}_{50}$ of imatinib dropping from $\sim 15 \mu \mathrm{M}$ to $\sim 5 \mu \mathrm{M}$, and the addition of $\mathrm{LY} 294002$ (15 $\left.\mu \mathrm{M}\right)$ reduced the $\mathrm{IC}_{50}$ to $\sim 2 \mu \mathrm{M}$. (B) Cell cycle analysis indicated that 7.5 and $10 \mu \mathrm{M}$ imatinib treatment at $24 \mathrm{~h}$ resulted in significantly increased S-phase fraction, reduction of which was achieved by combination treatment with $15 \mu \mathrm{M}$ of $\mathrm{U} 0126$ and $10 \mu \mathrm{M}$ of imatinib at the same time-point. However such changes were not observed with the combination treatment with imatinib and LY294002 (data not shown). Fluorescent microscopy analysis confirmed the above results and indicated that the groups with 7.5 and $10 \mu \mathrm{M}$ imatinib had significantly increased BrdU staining fractions, which identify cells undergoing DNA synthesis in the S-phase. (C) Results from monolayer wound healing assays indicated that imatinib inhibits cell migration (reduced crawling across the wound area compared to the controls) at $48 \mathrm{~h}$ compared to that in the controls. (D) Cell migration assays confirmed the results in (C) and indicated that imatinib significantly reduces cell migration ( $\mathrm{*} \mathrm{p}<0.05)$. Further combinations of imatinib with either U0126 or LY294002 did not increase the inhibition of cell migration as compared to imatinib alone. PD20 and PD50 indicated 20 and $50 \mu \mathrm{M}$ of PD98059; LY7.5 and LY15 indicated 7.5 and $15 \mu \mathrm{M}$ of LY294002, respectively. The two concentrations of PD98059 and LY294002 resulted in two concentrations of the solvent DMSO, respectively, indicated as D1 and D2 (e.g. D1=DMSO concentration 0.13\%, $20 \mu \mathrm{M}$ PD98059; and D2=DMSO concentration 0.33\%, $50 \mu \mathrm{M}$ PD98059, same calculation refers to the LY294002 controls). 
Table II. Cell cycle analysis for S-phase fraction in U87MG glioma cells treated with imatinib or combination treatment.

\begin{tabular}{lcccc}
\hline Imatinib $(\mu \mathrm{M})$ & $\mathrm{U} 0126(\mu \mathrm{M})$ & $8 \mathrm{~h}$ & $24 \mathrm{~h}$ & $48 \mathrm{~h}$ \\
\hline 0 & 0 & $21.72 \pm 1.11$ & $17.58 \pm 1.68$ & $14.38 \pm 4.18$ \\
7.5 & 0 & $19.57 \pm 2.19$ & $39.78 \pm 4.66^{\mathrm{a}}$ & $23.78 \pm 5.84$ \\
10 & 0 & $24.06 \pm 4.15$ & $31.12 \pm 7.79^{\mathrm{b}}$ & $31.39 \pm 4.81^{\mathrm{b}}$ \\
10 & 15 & NA & $6.35 \pm 2.32^{\mathrm{c}}$ & NA \\
\hline
\end{tabular}

Cell cycle analysis indicated that, in the U87MG cells, the 7.5 and $10 \mu \mathrm{M}$ imatinib treatments at 24 and $48 \mathrm{~h}$ respectively, resulted in significantly increased S-phase fractions, the significant reduction of which was achieved by combination treatment with $15 \mu \mathrm{M}$ of U0126 and $10 \mu \mathrm{M}$ of imatinib at $24 \mathrm{~h} .{ }^{\mathrm{a}} \mathrm{p}<0.01,{ }^{\mathrm{b}} \mathrm{p}<0.05$ compared to the untreated control at the same time-points, respectively. ${ }^{\mathrm{c}} \mathrm{p}<0.01$ compared to $10 \mu \mathrm{M}$ of imatinib treatment alone at the same time-point. NA, not available.

Table III. Cell cycle analysis for G2/M and S-phase fractions in T98G glioma cells treated with imatinib treatment.

\begin{tabular}{|c|c|c|c|c|c|c|}
\hline \multirow[b]{2}{*}{ Imatinib $(\mu \mathrm{M})$} & \multicolumn{2}{|c|}{$24 \mathrm{~h}$} & \multicolumn{2}{|c|}{$48 \mathrm{~h}$} & \multicolumn{2}{|c|}{$72 \mathrm{~h}$} \\
\hline & $\mathrm{G} 2 / \mathrm{M}$ & $\mathrm{S}$ & $\mathrm{G} 2 / \mathrm{M}$ & $\mathrm{S}$ & $\mathrm{G} 2 / \mathrm{M}$ & $\mathrm{S}$ \\
\hline 0 & $4.61 \pm 2.62$ & $39.85 \pm 7.21$ & $3.08 \pm 1.36$ & $35.70 \pm 3.22$ & $3.62 \pm 1.00$ & $35.62 \pm 6.36$ \\
\hline 5 & $5.29 \pm 2.83$ & $39.41 \pm 8.53$ & $5.69 \pm 2.15$ & $29.94 \pm 4.24$ & $7.09 \pm 1.55^{\mathrm{b}}$ & $28.22 \pm 4.22$ \\
\hline 7.5 & $4.83 \pm 2.98$ & $40.73 \pm 4.79$ & $6.55 \pm 1.56^{\mathrm{b}}$ & $30.46 \pm 3.37$ & $9.15 \pm 0.28^{\mathrm{a}}$ & $29.35 \pm 8.45$ \\
\hline
\end{tabular}

Cell cycle analysis indicated that $5 \mu \mathrm{M}$ at $48 \mathrm{~h}$ and $7.5 \mu \mathrm{M}$ imatinib treatments at $48 \mathrm{~h}, 72 \mathrm{~h}$, respectively, resulted in significantly increased $\mathrm{G} 2 / \mathrm{M}$ fractions in T98G cells, whose S-phase fractions were not affected by the treatment. ${ }^{\mathrm{a}} \mathrm{p}<0.01,{ }^{\mathrm{b}} \mathrm{p}<0.05$ compared to the untreated control at the same time-points, respectively.

U118MG and U373MG) in experimental settings similar to ours, have shown that the imatinib treatment did not have anti-proliferative activity at concentrations up to $10 \mu \mathrm{M}$ (28).

Further combination of imatinib with either PD98059 or LY294002 significantly increased the growth inhibition effect in U87MG cells compared to treatment with imatinib alone (Fig. 6A). These results show that while lower concentrations of imatinib alone inhibit cell proliferation inefficiently, combinations with either the MEK inhibitor, PD98059, or the PI3K inhibitor, LY294002, reduce imatinib resistance in U87MG significantly ( $<<0.01)$ (Fig. 6A). Cell cycle analysis in U87MG cells indicated that the S-phase fraction was significantly increased by increasing concentrations of imatinib treatment. Combination of imatinib with the MEK inhibitor, U0126, decreased the S-phase fraction (Fig. 6B and Table II). This was also confirmed by fluorescent microscopy with BrdU antibody staining in the cells without treatment (Fig. 6B). The results from cell cycle analysis in T98G glioma cells under imatinib treatment, however, did not show significant increase in S-phase fractions, but indicated increase in $\mathrm{G} 2 / \mathrm{M}$ fractions, compared to the respective controls (Table III). Variations in sensitivity to imatinib treatment between the two glioma cells could partially account for such differences (Fig. 1C). Moreover, the alteration pattern was not clear on the cell cycle data obtained from deployed RG glioma cells under imatinib treatment (data not shown).

However, data from cell migration assays and monolayer wound healing assays showed that imatinib treatment signifi- cantly inhibited glioma cell migration in U87MG cells in a dose- and time-dependent manner (Fig 6C and 6D, and other data not shown). However, combination therapies did not significantly improve the efficacy of cell migration inhibition (Fig. 6D). In our previous study, the parallel examination of the drugs effects on both cell migration and growth in U87MG cells, revealed the dichotomy of growth stimulation and migration inhibition, with the growth stimulation effect starting from $5 \mu \mathrm{M}$ and appearing most significant at $10 \mu \mathrm{M}$ of imatinib treatment, while migration inhibition occurred in a dose-dependent manner (21). Moreover, the alteration pattern was not clear on the cell migration data obtained from T98G and RG glioma cells under imatinib treatment (data not shown).

\section{Discussion}

The present study used cell culture-based assays to examine the cellular and molecular effects of the small molecule RTK inhibitor, imatinib mesylate, in a panel of malignant glioma cell lines, NIH3T3 fibroblast and K562 CML cells. We demonstrate here that imatinib is ineffective in inhibiting the activation of one of its targets, PDGFRB, when the activation of the target protein kinase is relatively low in glioma cells before treatment. It could further induce the constitutive activation of ERK signaling and the activation of other related downstream signaling pathways, leading to complicated cellular signaling and aberrant cell functions i.e., increase in 
cell proliferation in a subset of tested cells. However, imatinib treatment significantly inhibits the migration of some of the tested glioblastoma cells in a dose- and time-dependent manner.

Although the field of kinase inhibitors is being intensely explored in basic and clinical research, especially for cancer therapies, many questions remain unanswered. So far, the best targets in cancer are kinases that are constitutively activated by mutations. There is certain evidence that an overexpressed, but otherwise wild-type kinase, is a clinically useful target for a small molecule RTK inhibitor $(4,29)$. This has been exemplified by the dramatic clinical success of imatinib treatment in patients with CML with the expression of the mutant protein kinase, Bcr-Abl (14). In our results, highly activated Bcr-Abl in K562 CML cells and PDGFRB in NIH3T3 fibroblast cells stimulated by PDGF-BB, were both efficiently inhibited by relatively low concentrations of imatinib. More importantly, however, in other cell lines where the activation of the target protein kinase was relatively low, imatinib treatment was not only ineffective but also provoked unstable responses, including the constitutive and sustained activation of ERK and the activation of other downstream signaling effectors. In contrast, ERK activity was efficiently suppressed by imatinib at concentrations which achieved significant inhibition of phospho-Bcr-Abl in K562 cells at the times tested. ERK1/2 (p44/p42MAPK) plays a pivotal role in the integration of signals from extracellular stimuli regulating cell proliferation, differentiation and survival (25). Other relevant studies using glioma cell lines, including U87MG cells, have reported that the constitutive activation of ERK or Akt in the absence of a RTK inhibitor could be related to resistance against imatinib $(7,28,30,31)$. The activation of ERK by imatinib treatment was found in malignant glioma cells, including U87MG (31), squamous carcinoma (32), Bcr-Abl positive CML CD34+ (33) and K562 cells (24). Consistent with our results, Servidei et al found that increased PDGF-BB signaling sensitized chemoresistant glioma cells to imatinib treatment (31), while Pandiella et al indicated that imatinib was ineffective in inhibiting the activity of Bcr-Abl if the level of the kinase phosphorylation was relatively low (34). However, the results from Bcr-Abl-positive CML $\mathrm{CD} 4^{+}$and $\mathrm{K} 562$ cells showed that, although imatinib exposure resulted in a significant dose-responsive reduction in Bcr-Abl kinase activity, the treatment also resulted in an increase in the activity of the downstream effector, ERK, especially at later treatment intervals $(24,33)$, pointing out that the increased ERK activity in imatinib-treated cells could represent a compensatory response to the inhibition of Bcr-Abl tyrosine kinase activity. In our study, gene knockdown of PDGFRB by siRNA in U87MG cells resulted in the activation of Akt, possibly due to the activities of the feedback mechanisms. Nonetheless, this suggests that combination treatment with imatinib and ERK, or Akt inhibitors, could be a better treatment strategy for these malignancies.

The co-activation of alternative RTK was demonstrated in a relevant study with glioma cell lines, in which simultaneous multi-targeted therapy by combination of several RTK inhibitors proved to be necessary for the inhibition of the downstream PI3K signaling pathway (26). Alternatively, Johnson et al reported the activation of EGFR in imatinib- treated squamous carcinoma cells leading to increased activity of downstream ERK signaling (32). In our study, phospho-VEGFR was undetected by Western blotting and the activation of EGFR was not found in the imatinib-treated glioma cells (data not shown). Yet we showed that sunitinib (a multiple kinase inhibitor for PDGFR, VEGFR etc.), or combination treatment with erlotinib (an EGFR kinase inhibitor) and sunitinib, or treatment with imatinib and erlotinib, or sunitinib, paradoxically induces the activation of ERK at selected time-point of the treatment. This new finding warrants further detailed investigations. These results together with the recently recognized fact that imatinib could have further targets above and beyond Bcr-Abl, c-Kit and PDGFR (35), indicate that, in our tested glioma cells whose activity of PDGFR was low and/or lacked c-Kit expression, the growth inhibition effect or even the sustained activation of ERK by imatinib treatment could be caused by the action of the drug on yet unknown targets. However, the activation of ERK signaling could have different outcomes depending on the amplitude and duration of signal, the activity of the feedback mechanisms, and the interactions with other signaling pathways (36). In our study, although the combination treatment of LY294002, a PI3K inhibitor, with imatinib did not inhibit ERK activation in U87MG cells as shown by Western blotting, the treatment regimen resulted in increased suppression of U87MG cell growth compared to the imatinib treatment alone. These results suggest that continued signaling through the PI3K pathway could still contribute to the maintenance of the viability of imatinib-treated U87MG cells and that further inhibition of PI3K signaling can enhance the inhibition of cell growth.

Serious doubts have been raised as to whether RTK inhibitors indeed block their respective targets or whether the treatment induces activation effects. Results from a clinical trial in breast cancer have indicated that the multi-kinase inhibitor, vandetanib, whose targets include EGFR, VEGFR and RET, does not show any anti-tumor activity. Further evidence has indicated that the drug does not inhibit its targets, i.e. EGFR and VEGFR (37). In another study with glioma xenografts, although vandetanib was found to have certain anti-tumor activities, microvascular density, a typical marker of angiogenic activity, surprisingly increased, again raising doubts regarding the anti-angiogenic effects of the drug (38). Furthermore, results from clinical trials in recurrent glioblastoma with single-agent tyrosine kinase inhibitors, including imatinib and erlotinib, have shown that progressionfree survival at six months with erlotinib was $12 \%$ only, compared to $24 \%$ with the control (39). No responses were observed with erlotinib, and no correlations could be shown between treatment effect and EGFR/EGFRvIII expression or amplification. Moreover, EGFRvIII expression was correlated with decreased overall and progression-free survival in all patients. Disease progressed in all patients with EGFRvIII and PTEN co-expression treated with erlotinib $(17,39)$.

Glioblastomas are extremely heterogeneous malignancies with multiple molecular dysfunctions $(4,40)$. Clinical experience with molecularly targeted agents in patients with malignant gliomas have further demonstrated that, up to date, none of the selected molecular abnormalities, i.e. overexpressed or activated RTKs, including EGFR, PDGFR and 
VEGFR, proved to be a prevalent target, such as Bcr-Abl in CML $(4,5,39)$. However, severe inhibition of the activity of a single molecular target or the application of RTK inhibitors as single drugs could provoke unexpected effects in tumor cells other than glioma (41). In our study, the application of imatinib induced the activation of ERK, which was further proven to be related to increased proliferation and S-phase re-entry in U87MG but not the T98G, or RG glioblastoma cells. In addition, targeted gene knockdown of PDGFRB by siRNA resulted in the activation of Akt, which could be related to increased survival of the same glioblastoma cells. Therefore, compromising the activity of two or more individually dispensable targets by combination therapies could be a better way to induce lethal damage to tumor cells. Ziegler et al (42) have demonstrated that the inhibition of PDGFR in human glioblastoma cells is counteracted in the downstream apoptotic cascade by inhibitor-of-apoptosis proteins (IAP). They showed that the inhibition of PDGFR combined with small molecule inactivation of IAPs results in increased apoptosis in human glioblastoma cells (42). This concept of synthetic lethality is not entirely new, but has not been easy to apply to industrial drug design and discovery. Nonetheless, rational combinations of molecularly targeted agents are on the rise, although this area has not been well investigated in malignant gliomas $(7,29)$.

In conclusion, our results together with clinical data from other studies indicate that the imatinib treatment of malignant glioma does not result in significant inhibitory effects. Moreover, it can provoke the paradoxical activation of downstream signaling networks in subsets of malignant glioma cells and should be used with caution.

\section{Acknowledgements}

The present study was supported by the Key Project Science Foundation of Heilongjiang Province, China (grant-no. ZD200804-01), the Chinese Postdoctoral Fellowship (grantno. 2008043938), and the National Science Foundation of China (grant no. NFSC-30227738), to H.R., and also an HMU PhD Studentship (HCXB2010008) to Y.D.

\section{References}

1. Wen PY and Kesari S: Malignant gliomas in adults. N Engl J Med 359: 492-507, 2008.

2. Comprehensive genomic characterization defines human glioblastoma genes and core pathways. Nature 455: 1061-1068, 2008.

3. Ren H, Yang BF and Rainov NG: Receptor tyrosine kinases as therapeutic targets in malignant glioma. Rev Recent Clin Trials 2: 87-101, 2007

4. Omuro AM, Faivre S and Raymond E: Lessons learned in the development of targeted therapy for malignant gliomas. Mol Cancer Ther 6: 1909-1919, 2007.

5. De Witt Hamer PC: Small molecule kinase inhibitors in glioblastoma: a systematic review of clinical studies. Neuro Oncol 12: 304-316, 2010

6. Kesari S, Ramakrishna N, Sauvageot C, Stiles CD and Wen PY: Targeted molecular therapy of malignant gliomas. Curr Oncol Rep 8: 58-70, 2006.

7. Omuro AM: Exploring multi-targeting strategies for the treatment of gliomas. Curr Opin Investig Drugs 9: 1287-1295, 2008.

8. Hermanson M, Funa K, Hartman M, Claesson-Welsh L, Heldin $\mathrm{CH}$, Westermark B and Nistér M: Platelet-derived growth factor and its receptors in human glioma tissue: expression of messenger RNA and protein suggests the presence of autocrine and paracrine loops. Cancer Res 52: 3213-3219, 1992.
9. Maxwell M, Naber SP, Wolfe HJ, Galanopoulos T, HedleyWhyte ET, Black PM and Antoniades HN: Coexpression of platelet-derived growth factor (PDGF) and PDGF-receptor genes by primary human astrocytomas may contribute to their development and maintenance. J Clin Invest 86: 131-140, 1990.

10. Guha A, Dashner K, Black PM, Wagner JA and Stiles CD: Expression of PDGF and PDGF receptors in human astrocytoma operation specimens supports the existence of an autocrine loop. Int J Cancer 60: 168-173, 1995.

11. Vassbotn FS, Andersson M, Westermark B, Heldin CH and Ostman A: Reversion of autocrine transformation by a dominant negative platelet-derived growth factor mutant. Mol Cell Biol 13: 4066-4076, 1993

12. Kilic T, Alberta JA, Zdunek PR, et al: Intracranial inhibition of platelet-derived growth factor-mediated glioblastoma cell growth by an orally active kinase inhibitor of the 2-phenylaminopyrimidine class. Cancer Res 60: 5143-5150, 2000.

13. Shamah SM, Stiles CD and Guha A: Dominant-negative mutants of platelet-derived growth factor revert the transformed phenotype of human astrocytoma cells. Mol Cell Biol 13: 7203-7212, 1993.

14. Druker BJ: Imatinib as a paradigm of targeted therapies. Adv Cancer Res 91: 1-30, 2004.

15. Demetri GD, von Mehren M, Blanke CD, et al: Efficacy and safety of imatinib mesylate in advanced gastrointestinal stromal tumors. N Engl J Med 347: 472-480, 2002.

16. Cools J, DeAngelo DJ, Gotlib J, et al: A tyrosine kinase created by fusion of the PDGFRA and FIP1L1 genes as a therapeutic target of imatinib in idiopathic hypereosinophilic syndrome. $\mathrm{N}$ Engl J Med 348: 1201-1214, 2003.

17. Wen PY, Yung WK, Lamborn KR, et al: Phase I/II study of imatinib mesylate for recurrent malignant gliomas: North American Brain Tumor Consortium Study 99-08. Clin Cancer Res 12: 4899-4907, 2006.

18. Reardon DA, Egorin MJ, Quinn JA, et al: Phase II study of imatinib mesylate plus hydroxyurea in adults with recurrent glioblastoma multiforme. J Clin Oncol 23: 9359-9368, 2005.

19. Baruchel S, Sharp JR, Bartels U, et al: A Canadian paediatric brain tumour consortium (CPBTC) phase II molecularly targeted study of imatinib in recurrent and refractory paediatric central nervous system tumours. Eur J Cancer 45: 2352-2359, 2009.

20. Geoerger B, Morland B, Ndiaye A, et al: Target-driven exploratory study of imatinib mesylate in children with solid malignancies by the Innovative Therapies for Children with Cancer (ITCC) European Consortium. Eur J Cancer 45: 2342-2351, 2009.

21. Ren H, Tan X, Dong Y, Giese A, Chou TC, Rainov N and Yang B: Differential effect of imatinib and synergism of combination treatment with chemotherapeutic agents in malignant glioma cells. Basic Clin Pharmacol Toxicol 104: 241-252, 2009.

22. Davies SP, Reddy H, Caivano M and Cohen P: Specificity and mechanism of action of some commonly used protein kinase inhibitors. Biochem J 351: 95-105, 2000.

23. Demuth T, Hopf NJ, Kempski O, Sauner D, Herr M, Giese A and Perneczky A: Migratory activity of human glioma cell lines in vitro assessed by continuous single cell observation. Clin Exp Metastasis 18: 589-597, 2000.

24. Yu C, Krystal G, Varticovksi L, McKinstry R, Rahmani M, Dent $\mathrm{P}$ and Grant S: Pharmacologic mitogen-activated protein/extracellular signal-regulated kinase kinase/mitogenactivated protein kinase inhibitors interact synergistically with STI571 to induce apoptosis in Bcr/Abl-expressing human leukemia cells. Cancer Res 62: 188-199, 2002.

25. Newton HB: Molecular neuro-oncology and development of targeted therapeutic strategies for brain tumors. Part 1: Growth factor and Ras signaling pathways. Expert Rev Anticancer Ther 3: 595-614, 2003 .

26. Stommel JM, Kimmelman AC, Ying H, et al: Coactivation of receptor tyrosine kinases affects the response of tumor cells to targeted therapies. Science 318: 287-290, 2007.

27. Roskoski R Jr: Sunitinib: a VEGF and PDGF receptor protein kinase and angiogenesis inhibitor. Biochem Biophys Res Commun 356: 323-328, 2007.

28. Gross D, Bernhardt G and Buschauer A: Platelet-derived growth factor receptor independent proliferation of human glioblastoma cells: selective tyrosine kinase inhibitors lack antiproliferative activity. J Cancer Res Clin Oncol 132: 589-599, 2006.

29. Kwak EL, Clark JW and Chabner B: Targeted agents: the rules of combination. Clin Cancer Res 13: 5232-5237, 2007.

30. Hagerstrand D, Hesselager G, Achterberg S, et al: Characterization of an imatinib-sensitive subset of high-grade human glioma cultures. Oncogene 25: 4913-4922, 2006. 
31. Servidei T, Riccardi A, Sanguinetti M, Dominici C and Riccardi R: Increased sensitivity to the platelet-derived growth factor (PDGF) receptor inhibitor STI571 in chemoresistant glioma cells is associated with enhanced PDGF-BB-mediated signaling and STI571-induced Akt inactivation. J Cell Physiol 208: 220-228, 2006.

32. Johnson FM, Saigal B and Donato NJ: Induction of heparinbinding EGF-like growth factor and activation of EGF receptor in imatinib mesylate-treated squamous carcinoma cells. J Cell Physiol 205: 218-227, 2005.

33. Chu S, Holtz M, Gupta M and Bhatia R: BCR/ABL kinase inhibition by imatinib mesylate enhances MAP kinase activity in chronic myelogenous leukemia $\mathrm{CD} 34^{+}$cells. Blood 103: 3167-3174, 2004.

34. Pandiella A, Carvajal-Vergara X, Tabera S, Mateo G, Gutierrez N and San Miguel JF: Imatinib mesylate (STI571) inhibits multiple myeloma cell proliferation and potentiates the effect of common antimyeloma agents. Br J Haematol 123: 858-868, 2003.

35. Fabian MA, Biggs WH III, Treiber DK, et al: A small molecule-kinase interaction map for clinical kinase inhibitors. Nat Biotechnol 23: 329-336, 2005

36. Shaw RJ and Cantley LC: Ras, PI(3)K and mTOR signalling controls tumour cell growth. Nature 441: 424-430, 2006.
37. Heymach JV: ZD6474-clinical experience to date. Br J Cancer 92 (Suppl 1): 14-20, 2005.

38. Sandstrom M, Johansson M, Andersson U, Bergh A, Bergenheim AT and Henriksson R: The tyrosine kinase inhibitor ZD6474 inhibits tumour growth in an intracerebral rat glioma model. Br J Cancer 91: 1174-1180, 2004.

39. Brandes AA, Franceschi E, Tosoni A, Hegi ME and Stupp R: Epidermal growth factor receptor inhibitors in neuro-oncology: hopes and disappointments. Clin Cancer Res 14: 957-960, 2008.

40. Wen PY and Kesari S: Malignant gliomas. Curr Neurol Neurosci Rep 4: 218-227, 2004.

41. Ebos JM, Lee CR, Cruz-Munoz W, Bjarnason GA, Christensen JG and Kerbel RS: Accelerated metastasis after short-term treatment with a potent inhibitor of tumor angiogenesis. Cancer Cell 15: 232-239, 2009.

42. Ziegler DS, Wright RD, Kesari S, et al: Resistance of human glioblastoma multiforme cells to growth factor inhibitors is overcome by blockade of inhibitor of apoptosis proteins. J Clin Invest 118: 3109-3122, 2008. 